\title{
Comparative Evaluation of Hard-Tissue and Soft-Tissue Changes following Fixed Functional Appliance Treatment in a Skeletal Class II Malocclusion Using Forsus and PowerScope
}

\author{
Prajwal Shetty $^{1}$ Mukul Shetty ${ }^{1}$ Maitreyi Chalapati ${ }^{2}$ \\ ${ }^{1}$ Department of Orthodontics and Dentofacial Orthopaedics, A.B. \\ Shetty Memorial Institute of Dental Science, Nitte (Deemed to be) \\ University, Deralakatte, Karnataka, India \\ ${ }^{2}$ Orthodontics and Dentofacial Orthopaedics, Private Clinic, \\ Hyderabad, Telangana, India \\ ${ }^{3}$ Orthodontics and Dentofacial Orthopaedics, Private Clinic, Hubli, \\ Karnataka, India
}

J Health Allied Sci ${ }^{\mathrm{Nu}: 2021 ; 11: 87-92}$

\author{
Chaitra Kori $^{3} \quad$ Crystal Runa Soans $^{1} \quad$ Murali P.S. $^{1}$
}

\begin{abstract}
Address for correspondence Mukul Shetty, MDS, Department of Orthodontics and Dentofacial Orthopaedics, A.B. Shetty Memorial Institute of Dental Science, Nitte (Deemed to be) University, Deralakatte 575018, Karnataka, India., (e-mail: drmukulshetty@nitte.edu.in).
\end{abstract}

\begin{abstract}
Keywords

- retrognathic mandible

- skeletal class II

malocclusion

- Forsus appliance

- PowerScope appliance

Introduction The purpose of this study was to evaluate and compare the skeletal, dentoalveolar and soft-tissue effects of 2 fixed functional appliance; Forsus Fatigue Resistance Device (FFRD) and PowerScope appliance in treating patients with skeletal class II division 1 malocclusion.

Materials and Methods This comparative prospective two-group study included 20 patients with a mean age of $11.2 \pm 1.6$ years with skeletal class II malocclusion with retrognathic mandible. One group was treated with FFRD, and second group was treated with PowerScope appliance. Lateral cephalograms were evaluated at T1 (pre-functional appliance treatment)) and at T2 (postappliance treatment). Cephalometric values were calculated and assessed to evaluate skeletal, dentoalveolar and soft-tissue changes.

Results Sagittal correction of class II malocclusion appeared to be mainly achieved by dentoalveolar changes in the PowerScope group. The FFRD was able to induce both skeletal and dentoalveolar changes. A favorable influence on facial convexity was achieved by both groups. A significant increase in upper pharynx and lower pharynx dimension was seen in the PowerScope group. A statistically significant decrease in upper lip protrusion, increase in lower lip protrusion, increased nasolabial angle, and decrease in inferior labial sulcus were noted in both the groups. Lower incisors proclined more in the PowerScope group.

Conclusion Both appliances were effective in correcting class II malocclusion. Forsus had more skeletal effects on the mandible, whereas PowerScope had less skeletal effects on the mandible and more dentoalveolar effects, contributing to class II correction. Both groups showed a significant improvement in soft-tissue profile. PowerScope group showed a significant increase in airway dimensions.
\end{abstract}

published online

February 10, 2021
DOI https://doi.org/

$10.1055 / \mathrm{s}-0041-1722821$ ISSN 2582-4287.

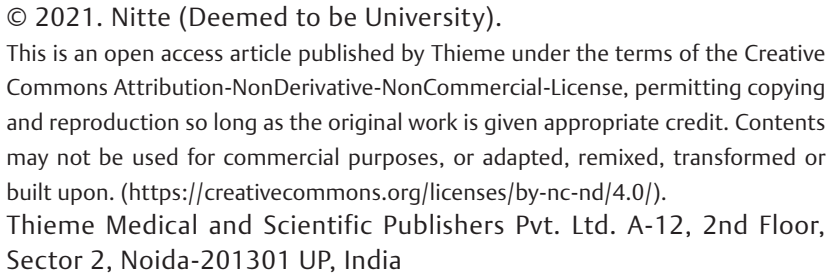
Commons Attribution-NonDerivative-NonCommercial-License, permitting copying and reproduction so long as the original work is given appropriate credit. Contents may not be used for commercial purposes, or adapted, remixed, transformed or built upon. (https://creativecommons.org/licenses/by-nc-nd/4.0/). Thieme Medical and Scientific Publishers Pvt. Ltd. A-12, 2nd Floor, Sector 2, Noida-201301 UP, India 


\section{Introduction}

Treatment of a growing patient with skeletal class II malocclusion presents a major challenge to orthodontists. ${ }^{1}$ Mandibular retrusion is one of the most common characteristics of a class II malocclusion. One of the recommended therapeutic approaches to skeletal class II malocclusion in growing patients is functional jaw orthopaedics through the primary mechanism of mandibular advancement. ${ }^{2}$ Various removable and fixed functional appliances are commonly used to stimulate mandibular growth by the forward positioning of the mandible. ${ }^{3}$

Major limitations of removable functional appliances are the need for patient collaboration and the lack of the possibility of combining the use of the functional appliance with multibracket therapy to shorten treatment duration. ${ }^{4}$ Fixed devices for sagittal advancement of the mandible that can be worn in association with fixed appliances have been introduced to the orthodontic community to overcome these limitations.

Various fixed functional appliances have been used to achieve this forward growth such as Eureka Spring, Jasper Jumper, Herbst appliance, mandibular protraction appliance, Forsus Fatigue Resistant Device (FFRD), and PowerScope appliance. Among these wide range of fixed functional appliances, the task of choosing a best appliance is challenging. In the present study, skeletal and dental changes with PowerScope appliance and Forsus appliance were compared and assessed.

PowerScope class II corrector and its unique features have a patient-friendly design, ready to use one piece with no laboratory setup and no assembly. It has a simple attachment system with durable telescopic mechanism, a Ni-Ti internal spring system and a ball and socket joint system that maximizes lateral movement for patient comfort. ${ }^{5}$

The FFRD is a semirigid telescoping system incorporating a superelastic nickel-titanium coil spring that can be assembled chair-side and that can be used in conjunction with complete fixed orthodontic appliances. The FFRD attaches at the maxillary first molar and onto the mandibular archwire, distal to either the canine or the first premolar bracket.

Thus, this study aims to compare the skeletal, dentoalveolar, soft-tissue changes, airway dimensions, and hyoid positions, produced by Forsus and PowerScope fixed functional appliance in a skeletal class II malocclusion.

\section{Materials and Methods}

This was a comparative prospective two-group clinical study. A total of 20 patients with a mean age of $11.2 \pm 1.6$ years with skeletal class II malocclusion reporting to the department of orthodontics and dentofacial orthopaedics were consulted and selected for treatment with fixed functional appliances. Patients were randomly divided into two equal groups of 10 subjects among PowerScope and Forsus group. Randomization was done using a simple randomization method to ensure allocation ratio of 1:1 in both the groups.
The name of the groups "Forsus" and "PowerScope" was written on 20 pieces of paper and was placed inside identical looking envelopes. They were then sealed and placed in a box. The envelopes were shuffled inside the box, and each patient was told to pick one envelope from the box. The patient was then assigned to the designated group. Informed consent was attained from the patient prior to the start of this study.

Only those patients who were starting or within the period of their skeletal growth spurt, as indicated by the cervical vertebral maturation method, were included in the study. Only patients with retrognathic mandible and having molars and canine in class II relation or in an end-on relation were included in this study. Visual treatment objective (VTO) was checked and only those demonstrating a positive VTO were included in the study. Participants with a history of orthodontic treatment were not included in the study. Patients with any systemic diseases affecting bone and general growth were excluded from the study. Treatment plan was nonextraction line of treatment with mandibular advancement with fixed functional appliance.

All subjects were bonded in both the arches with preadjusted edgewise appliance with MBT prescription (0.022" slot). Initial leveling and aligning were continued until the wire $0.019 \times 0.025$ stainless steel was passively engaging in the brackets of both upper and lower arches. The archwire distal to the molars was cinched in mandible. Lateral cephalogram was taken at this stage (T1). Lateral cephalograms were made under standardized conditions with the Frankfort horizontal plane kept parallel to the floor and the midfacial plane kept in a vertical position. The tracing of lateral cephalograms was done on the Nemoceph software. Cephalometric measurements were calculated. FFRD and PowerScope were used respectively in the subjects of assigned group. Appliance was kept in the mouth until class I molar relation was obtained. Post functional appliance treatment, second lateral cephalogram (T2) was taken and cephalometric values were calculated. Mean treatment duration was $0.7 \pm 0.1$ months. Post functional cephalogram was taken and skeletal, dental and soft-tissue measurements were measured.

\section{Cephalometric Analysis}

The following measurements were made on the lateral cephalograms:

1. SNA: The angle formed by joining lines SN and NA.

2. SNB: The angle formed by joining the lines SN and NB.

3. ANB: The angle formed between NA and NB.

4. Sn-GoGn: The angle formed between the SN plane and GoGn plane.

5. IMPA (incisor mandibular plane angle): Angle formed between the long axis of lower incisor to the mandibular plane.

6. Sn-U1: The angle formed between the long axis of upper incisor to the $\mathrm{SN}$ plane.

7. $\mathrm{N} \perp$ point $\mathrm{B}$ : The linear distance measured from perpendicular drawn from nasion to point $B$. 
8. Interincisal angle: This angle is established by passing a line through the incisal edge and the apex of the root of the maxillary and mandibular central incisors.

9. FMA (Frankfort mandibular plane angle): The angle formed between Frankfort horizontal plane and mandibular plane.

10. OP-SN: The angle formed between occlusal plane to $\mathrm{Sn}$ plane.

11. Upper lip protrusion: Perpendicular distance between upper lip anterior and the subnasale-pogonion line.

12. Lower lip protrusion: Perpendicular distance between lower lip anterior and the subnasale-pogonion line.

13. Nasolabial angle: It is defined as the angle between the line drawn through the midpoint of the nostril aperture and a line drawn perpendicular to the Frankfurt horizontal while intersecting subnasale.

14. Mentolabial sulcus depth: It is the perpendicular distance between the deepest point on the mentolabial sulcus to Li-Pg line.

15. Upper pharynx: It is measured from a point on the posterior outline of the soft palate to the closest point on the posterior pharyngeal wall

16. Lower pharynx: It is measured from the point of intersection of the posterior border of the tongue and its inferior border of the mandible to the closest point on posterior pharyngeal wall.

17. Hyoid to mandible: It is the linear distance measured from the hyoid bone to the mandible.

18. Hyoid triangle: The hyoid triangle relates the hyoid bone to the vertebrae and to the mandible.

\section{Statistical Analysis}

All the data collected were transferred to a computer, the results were statistically analyzed using the statistical software SPSS (version 20.0 IBM Corp, Armonk, New York, United States). The comparison of the mean values before and after treatment with Forsus appliance and PowerScope appliance was done using paired $t$-test. Unpaired $t$-test was used to calculate mean value between Forsus and PowerScope appliance.

\section{Results}

Lateral cephalogram of all 20 subjects was evaluated before and after the end of fixed functional appliance treatment. When a paired $t$-test was performed for comparison of preand post-treatment values of Forsus fixed functional appliance, class II correction happened by, significant decrease in ANB angle, decreased upper incisor proclination, decreased $\mathrm{N}$ perpendicular-point B, increased interincisal angle ( - Table $\mathbf{1}$ ).

When an paired $t$-test was performed for comparison of pre- and post-treatment values of PowerScope fixed functional appliance, class II correction happened by significant increase in IMPA angle, decreased upper incisor proclination, increased lower incisor proclination. Significant increase in upper pharynx and lower pharynx dimensions were noticed post-treatment indicating increase in airway dimensions in PowerScope group (-Table 2).
Table 1 Comparison of cephalometric values between prefunctional and post-functional appliance treatment using Forsus Fatigue Resistant Device

\begin{tabular}{|c|c|c|c|c|}
\hline $\begin{array}{l}\text { Cephalometric } \\
\text { values }\end{array}$ & & Mean & $\begin{array}{l}\text { Standard } \\
\text { deviation }\end{array}$ & $p$-Value \\
\hline \multirow[t]{2}{*}{ SNA } & Pre & 82.00 & 4.570 & \multirow[t]{2}{*}{$0.005^{\mathrm{a}}$} \\
\hline & Post & 79.80 & 4.367 & \\
\hline \multirow[t]{2}{*}{ SNB } & Pre & 76.80 & 4.940 & \multirow[t]{2}{*}{0.794} \\
\hline & Post & 76.60 & 3.438 & \\
\hline \multirow[t]{2}{*}{ ANB } & Pre & 5.20 & 1.033 & \multirow[t]{2}{*}{$0.001^{\mathrm{a}}$} \\
\hline & Post & 3.00 & 1.155 & \\
\hline \multirow[t]{2}{*}{ Sn-goGn } & Pre & 27.50 & 5.701 & \multirow[t]{2}{*}{0.137} \\
\hline & Post & 26.70 & 6.038 & \\
\hline \multirow[t]{2}{*}{ IMPA } & Pre & 101.10 & 7.187 & \multirow[t]{2}{*}{0.163} \\
\hline & Post & 103.50 & 6.687 & \\
\hline \multirow[t]{2}{*}{ U1-Sn } & Pre & 118.50 & 9.698 & \multirow[t]{2}{*}{$0.001^{\mathrm{a}}$} \\
\hline & Post & 105.00 & 4.137 & \\
\hline \multirow[t]{2}{*}{$\mathrm{N} \perp$ point $\mathrm{B}$} & Pre & -8.20 & 3.676 & \multirow[t]{2}{*}{$0.003^{\mathrm{a}}$} \\
\hline & Post & -5.50 & 3.598 & \\
\hline \multirow[t]{2}{*}{ U1L1 } & Pre & 104.80 & 5.007 & \multirow[t]{2}{*}{$0.005^{\mathrm{a}}$} \\
\hline & Post & 115.00 & 8.882 & \\
\hline \multirow[t]{2}{*}{ FMA } & Pre & 26.30 & 5.755 & \multirow[t]{2}{*}{0.764} \\
\hline & Post & 26.50 & 5.603 & \\
\hline \multirow[t]{2}{*}{ OP-Sn } & Pre & 17.60 & 2.951 & \multirow[t]{2}{*}{$0.013^{a}$} \\
\hline & Post & 20.00 & 2.582 & \\
\hline \multirow[t]{2}{*}{ ULP } & Pre & 1.60 & 1.36 & \multirow[t]{2}{*}{$<0.001^{\mathrm{a}}$} \\
\hline & Post & -0.39 & 1.33 & \\
\hline \multirow[t]{2}{*}{ LLP } & Pre & 1.55 & 1.35 & \multirow[t]{2}{*}{$<0.001^{\mathrm{a}}$} \\
\hline & Post & 2.59 & 1.51 & \\
\hline \multirow[t]{2}{*}{ Nasolabial angle } & Pre & 105.70 & 15.13 & \multirow[t]{2}{*}{$<0.001^{\mathrm{a}}$} \\
\hline & Post & 115.50 & 12.46 & \\
\hline \multirow{2}{*}{$\begin{array}{l}\text { Inferior labial } \\
\text { sulcus }\end{array}$} & Pre & -5.46 & 1.24 & \multirow[t]{2}{*}{$<0.001^{\mathrm{a}}$} \\
\hline & Post & -3.73 & 1.26 & \\
\hline Hyoid to & Pre & -14.71 & 3.85 & $<0.001^{a}$ \\
\hline & Post & -16.69 & 3.77 & \\
\hline Hyoid triangle & Pre & 18.31 & 5.70 & $<0.001^{a}$ \\
\hline & Post & 24.62 & 6.04 & \\
\hline Upper pharynx & Pre & 13.01 & 1.26 & 0.65 \\
\hline & Post & 13.15 & 1.48 & \\
\hline Lower pharynx & Pre & 8.55 & 0.44 & 0.12 \\
\hline & Post & 8.68 & 0.34 & \\
\hline
\end{tabular}

${ }^{a} p$-Value $<0.05$ is considered statistically significant.

When an unpaired "t"-test was performed for comparison between Forsus and PowerScope fixed functional appliance groups class II correction happened, but there was significant decrease in ANB angle in Forsus then PowerScope group. There was increased lower incisor proclination in PowerScope group then that of Forsus group. Increased nasolabial angle was seen in both the groups (-Table 3). 
Comparative Evaluation of Hard and Soft Tissue Changes in a Skeletal Class II Malocclusion Using Forsus and PowerScope

Table 2 Comparison of cephalometric values between prefunctional and post-functional appliance treatment using PowerScope appliance

\begin{tabular}{|c|c|c|c|c|}
\hline $\begin{array}{l}\text { Cephalometric } \\
\text { values }\end{array}$ & & Mean & $\begin{array}{l}\text { Standard } \\
\text { deviation }\end{array}$ & $p$-Value \\
\hline \multirow[t]{2}{*}{ SNA } & Pre & 81.10 & 3.071 & \multirow[t]{2}{*}{0.052} \\
\hline & Post & 80.60 & 2.989 & \\
\hline \multirow[t]{2}{*}{ SNB } & Pre & 76.00 & 3.651 & \multirow[t]{2}{*}{0.193} \\
\hline & Post & 76.30 & 3.743 & \\
\hline \multirow[t]{2}{*}{ ANB } & Pre & 5.00 & 1.054 & \multirow[t]{2}{*}{0.081} \\
\hline & Post & 4.40 & 1.560 & \\
\hline \multirow[t]{2}{*}{ Sn-goGn } & Pre & 29.00 & 5.558 & \multirow[t]{2}{*}{$0.001^{\mathrm{a}}$} \\
\hline & Post & 32.10 & 6.045 & \\
\hline \multirow[t]{2}{*}{ IMPA } & Pre & 105.70 & 4.739 & \multirow[t]{2}{*}{$0.001^{\mathrm{a}}$} \\
\hline & Post & 112.60 & 4.904 & \\
\hline \multirow[t]{2}{*}{ U1-Sn } & Pre & 114.70 & 6.945 & \multirow[t]{2}{*}{$0.025^{\mathrm{a}}$} \\
\hline & Post & 110.00 & 6.272 & \\
\hline \multirow[t]{2}{*}{$\mathrm{N} \perp$ point $\mathrm{B}$} & Pre & -7.20 & 1.229 & \multirow[t]{2}{*}{0.273} \\
\hline & Post & -6.70 & 1.252 & \\
\hline \multirow[t]{2}{*}{ U1L1 } & Pre & 106.30 & 2.830 & \multirow[t]{2}{*}{$0.001^{\mathrm{a}}$} \\
\hline & Post & 114.10 & 7.233 & \\
\hline \multirow[t]{2}{*}{ FMA } & Pre & 23.70 & 3.622 & \multirow[t]{2}{*}{0.096} \\
\hline & Post & 24.90 & 4.306 & \\
\hline \multirow[t]{2}{*}{ OP-Sn } & Pre & 13.60 & 3.340 & \multirow[t]{2}{*}{$0.001^{\mathrm{a}}$} \\
\hline & Post & 16.00 & 3.830 & \\
\hline \multirow[t]{2}{*}{ ULP } & Pre & 2.46 & 1.17 & \multirow[t]{2}{*}{$<0.001^{a}$} \\
\hline & Post & 0.053 & 0.68 & \\
\hline \multirow[t]{2}{*}{ LLP } & Pre & 3.64 & 1.15 & \multirow[t]{2}{*}{$0.001^{\mathrm{a}}$} \\
\hline & Post & 4.65 & 1.07 & \\
\hline \multirow{2}{*}{$\begin{array}{l}\text { Nasolabial } \\
\text { angle }\end{array}$} & Pre & 99.50 & 7.74 & \multirow[t]{2}{*}{$<0.001^{\mathrm{a}}$} \\
\hline & Post & 118.90 & 5.86 & \\
\hline \multirow{2}{*}{$\begin{array}{l}\text { Inferior labial } \\
\text { sulcus }\end{array}$} & Pre & -3.98 & 0.63 & \multirow[t]{2}{*}{$0.01^{\mathrm{a}}$} \\
\hline & Post & -3.03 & 0.98 & \\
\hline Hyoid to & Pre & -9.97 & 1.75 & $0.007^{\mathrm{a}}$ \\
\hline mandible & Post & -12.25 & 2.18 & \\
\hline Hyoid triangle & Pre & 2.69 & 14.67 & 0.26 \\
\hline & Post & 4.73 & 18.53 & \\
\hline Upper pharynx & Pre & 12.27 & 1.61 & $0.006^{a}$ \\
\hline & Post & 13.22 & 1.62 & \\
\hline Lower pharynx & Pre & 8.16 & 0.53 & $0.006^{a}$ \\
\hline & Post & 8.33 & 0.53 & \\
\hline
\end{tabular}

${ }^{a} p$-Value $<0.05$ is considered statistically significant.

\section{Discussion}

The aim of this study was to evaluate and compare skeletal changes, dentoalveolar changes, soft-tissue changes, position of hyoid, and changes in airway produced by PowerScope and Forsus appliance. Nemoceph 2.0 software was used for the measurements.
The effects of functional appliances on the maxilla are inconsistent in the literature, with many previous studies showing no restriction in the forward growth of the maxilla, ${ }^{6,7}$ whereas others reported inhibition of maxillary growth. ${ }^{1,3,8}$ The current study showed significant restrictive effect on maxilla in both Forsus and PowerScope fixed functional appliance groups.

The study showed that the Forsus displayed a statistically significant difference $(p<0.05)$ in mandibular mesial movement when compared with the PowerScope. The statistically significant difference in skeletal mandibular changes between the Forsus and PowerScope groups may have been a result of the difference in the sites of attachments of the two appliances.

The greater dentoalveolar effects can be explained by the attachment of the PowerScope, which is completely on the archwires, making the appliance less rigid when compared with the Forsus. Also, an increased number of patient visits and more frequent breakage were reported with the PowerScope. ${ }^{9,10}$ The difference in effective treatment time for which the appliance was kept in the mouth for the Forsus was significantly more than for the PowerScope, and this may have allowed for more mandibular skeletal changes in the Forsus group than in the PowerScope group.

The maxillary dentition moved distally with both of the appliances. The distal movement of the maxillary molars was similar in both of the groups $(0.7 \mathrm{~mm})$, whereas the distal movement of the maxillary incisors was significantly greater in the Forsus group $(1.3 \mathrm{~mm})$ when compared with the PowerScope group $(0.8 \mathrm{~mm})$. This shows that more reciprocal force acted distally on the maxillary dental arch when the mandible was postured forward by the Forsus compared to the PowerScope. ${ }^{11}$

The dentoalveolar effects on the lower dental arch with both appliances were mesial movement of the lower molars and proclination of the lower incisors. These findings are in accordance with those reported in various other studies of fixed functional appliances ${ }^{11}$ and were a result of the downward and forward application of force on the mandibular dentition.

The mesial movement of the mandibular molar and incisors was greater in the PowerScope group (2.3 and $2.8 \mathrm{~mm}$, respectively) when compared with the Forsus group (1.9 and $2.3 \mathrm{~mm}$, respectively). As discussed, the difference in mode of attachment between the two appliances, with the PowerScope being completely attached on the archwires, may have led to more dentoalveolar changes. ${ }^{11}$

In the PowerScope and Forsus group, the upper lip protrusion was found to decrease and the lower lip protrusion was found to increase in both the groups. This was found to be statistically significant in both the groups. This could be attributed to that fact that lower jaw comes in a forward position with the functional appliance along with a slight retroclination of the upper incisors. ${ }^{3,6,7}$

Nasolabial angle was found to increase in the PowerScope and Forsus group and this was found to be 
Table 3 Comparison of pre- and post-functional appliance treatment changes between Forsus Fatigue Resistant Device and PowerScope appliance

\begin{tabular}{|c|c|c|c|c|c|c|}
\hline \multirow[t]{2}{*}{ Cephalometric values } & & \multicolumn{2}{|c|}{ Mean } & \multicolumn{2}{|c|}{ Standard deviation } & \multirow[t]{2}{*}{$p$-Value } \\
\hline & & Forsus & PowerScope & Forsus & PowerScope & \\
\hline \multirow[t]{2}{*}{ SNA } & Pre & 82.00 & 81.10 & 4.570 & 3.071 & 0.612 \\
\hline & Post & 79.80 & 80.60 & 4.367 & 2.989 & 0.638 \\
\hline \multirow[t]{2}{*}{ SNB } & Pre & 76.80 & 76.00 & 4.940 & 3.651 & 0.685 \\
\hline & Post & 76.60 & 76.30 & 3.438 & 3.743 & 0.854 \\
\hline \multirow[t]{2}{*}{ ANB } & Pre & 5.20 & 5.00 & 1.033 & 1.054 & 0.673 \\
\hline & Post & 3.00 & 4.40 & 1.155 & 1.560 & $0.031^{\mathrm{a}}$ \\
\hline \multirow[t]{2}{*}{ Sn-goGn } & Pre & 27.50 & 29.00 & 5.701 & 5.558 & 0.559 \\
\hline & Post & 26.70 & 32.10 & 6.038 & 6.045 & 0.061 \\
\hline \multirow[t]{2}{*}{ IMPA } & Pre & 101.10 & 105.70 & 7.187 & 4.739 & 0.108 \\
\hline & Post & 103.50 & 112.60 & 6.687 & 4.904 & $0.003^{\mathrm{a}}$ \\
\hline \multirow[t]{2}{*}{ U1-Sn } & Pre & 118.50 & 114.70 & 9.698 & 6.945 & 0.327 \\
\hline & Post & 105.00 & 110.00 & 4.137 & 6.272 & 0.052 \\
\hline \multirow[t]{2}{*}{$N \perp$ point $B$} & Pre & -8.20 & -7.20 & 3.676 & 1.229 & 0.425 \\
\hline & Post & -5.50 & -6.70 & 3.598 & 1.252 & 0.332 \\
\hline \multirow[t]{2}{*}{ U1L1 } & Pre & 104.80 & 106.30 & 5.007 & 2.830 & 0.420 \\
\hline & Post & 115.00 & 114.10 & 8.882 & 7.233 & 0.807 \\
\hline \multirow[t]{2}{*}{ FMA } & Pre & 26.30 & 23.70 & 5.755 & 3.622 & 0.242 \\
\hline & Post & 26.50 & 24.90 & 5.603 & 4.306 & 0.483 \\
\hline \multirow[t]{2}{*}{ OP-Sn } & Pre & 17.60 & 13.60 & 2.951 & 3.340 & $0.011^{\mathrm{a}}$ \\
\hline & Post & 20.00 & 16.00 & 2.582 & 3.830 & $0.015^{\mathrm{a}}$ \\
\hline \multirow[t]{2}{*}{ ULP } & Pre & 1.60 & 2.46 & 1.36 & 1.17 & \multirow[t]{2}{*}{0.87} \\
\hline & Post & -0.39 & 0.053 & 1.33 & 0.68 & \\
\hline \multirow[t]{2}{*}{ LLP } & Pre & 1.55 & 3.64 & 1.35 & 1.15 & \multirow[t]{2}{*}{0.90} \\
\hline & Post & 2.59 & 4.65 & 1.51 & 1.07 & \\
\hline \multirow[t]{2}{*}{ Nasolabial angle } & Pre & 105.70 & 99.50 & 15.13 & 7.74 & \multirow[t]{2}{*}{$0.01^{\mathrm{a}}$} \\
\hline & Post & 115.50 & 118.90 & 12.46 & 5.86 & \\
\hline \multirow[t]{2}{*}{ Inferior labial sulcus } & Pre & -5.46 & -3.98 & 1.24 & 0.63 & \multirow[t]{2}{*}{0.08} \\
\hline & Post & -3.73 & -3.03 & 1.26 & 0.98 & \\
\hline \multirow[t]{2}{*}{ Hyoid to mandible } & Pre & -14.71 & -9.97 & 3.85 & 1.75 & \multirow[t]{2}{*}{0.67} \\
\hline & Post & -16.69 & -12.25 & 3.77 & 2.18 & \\
\hline \multirow[t]{2}{*}{ Hyoid triangle } & Pre & 18.31 & 2.69 & 5.70 & 14.67 & \multirow[t]{2}{*}{$0.04^{\mathrm{a}}$} \\
\hline & Post & 24.62 & 4.73 & 6.04 & 18.53 & \\
\hline \multirow[t]{2}{*}{ Upper pharynx } & Pre & 13.01 & 12.27 & 1.26 & 1.61 & 0.06 \\
\hline & Post & 13.15 & 13.22 & 1.48 & 1.62 & \\
\hline Lower pharynx & Pre & 8.55 & 8.16 & 0.44 & 0.53 & 0.66 \\
\hline & Post & 8.68 & 8.33 & 0.34 & 0.53 & \\
\hline
\end{tabular}

${ }^{a} p$-Value $<0.05$ is considered statistically significant

statistically significant. This could be attributed to the fact that a reciprocal distal force is acted on the maxillary arch when the mandible was postured forwardly in both the appliances. ${ }^{3,12}$

An increased value of inferior labial sulcus is seen in class II individuals with normal chin. This is due to the deficient mandible seen in class II cases. A significant decrease in its value is seen in both the groups and this signifies a greater mesial dentoalveolar change in the mandible on protrusion. According to various other studies, a significant dentoalveolar effect is seen in the mesial direction on the lower arch..$^{8,12}$

The upper lip retrusion, lower lip protrusion, increased nasolabial angle, and decreased inferior labial sulcus all together showed a significant improvement in the convex profile of a class II patient. ${ }^{8,9}$

Skeletal class II malocclusion due to mandibular retrusion was reported to be a risk factor for upper and lower 
airway deficiencies. ${ }^{10,13}$ The importance of the deficiency in the airway is that it is related to breathing disorders that may affect the pulmonary ventilation, oxygenation, sleep quality, sweating, and nocturnal enuresis. ${ }^{14}$ Therefore, the correction of mandibular retrusion using intraoral appliances is expected to improve the pharyngeal airway deficiency. ${ }^{15}$ In this study, the PowerScope group showed a significant increase in airway dimensions, whereas the increase in Forsus group was not statistically significant.

Previous studies ${ }^{16,17}$ demonstrated that the hyoid bone is posteriorly positioned in patients with skeletal class II malocclusion due to mandibular retrusion and forward movement of the mandible improves the position of hyoid bone and thus the pharyngeal airway deficiency. In this study, hyoid bone displacement in the more forward direction was noted for both the groups and this was statistically significant. This was in correlation to the previous studies. ${ }^{6,11}$

On comparison both the PowerScope and Forsus group showed an improvement in soft-tissue profile that was similar in magnitude. A greater increase in nasolabial angle was seen in the PowerScope group in comparison to the Forsus group that was statistically significant.

\section{Conclusion}

The following conclusions can be made from the study:

- Both the fixed functional appliances were effective in correcting class II malocclusion.

- Forsus had more skeletal effects on the mandible, whereas PowerScope had less skeletal effects on the mandible and more dentoalveolar effects, contributing to class II correction.

- In both groups, a significant improvement in soft-tissue profile was noted.

- PowerScope group showed a significant increase in airway dimensions, whereas the increase in Forsus group was not statistically significant.

\section{Conflict of Interest}

None declared.

\section{References}

1. Nelson B, Hansen K, Hägg U. Class II correction in patients treated with class II elastics and with fixed functional appliances: a comparative study. Am J Orthod Dentofacial Orthop 2000; 118(2):142-149
2. Flores-Mir C, Major MP, Major PW. Soft tissue changes with fixed functional appliances in Class II division 1. Angle Orthod 2006; 76(4):712-720

3. Jones G, Buschang PH, Kim KB, Oliver DR. Class II non-extraction patients treated with the Forsus Fatigue Resistant Device versus intermaxillary elastics. Angle Orthod 2008; 78(2):332-338

4. Franchi L, Alvetro L, Giuntini V, Masucci C, Defraia E, Baccetti T. Effectiveness of comprehensive fixed appliance treatment used with the Forsus Fatigue Resistant Device in Class II patients. Angle Orthod 2011; 81(4):678-683

5. Ozdemir F, Ulkur F, Nalbantgil D. Effects of fixed functional therapy on tongue and hyoid positions and posterior airway. Angle Orthod 2014; 84(2):260-264

6. Hanoun A, Al-Jewair TS, Tabbaa S, Allaymouni MA, Preston CB. A comparison of the treatment effects of the Forsus Fatigue Resistance Device and the Twin Block appliance in patients with class II malocclusions. Clin Cosmet Investig Dent 2014; 6:57-63

7. Gunay EA, Arun T, Nalbantgil D. Evaluation of the immediate dentofacial changes in late adolescent patients treated with the ForsusTM FRD. Eur J Dent 2011; 5(4):423-432

8. Paulose J, Antony PJ, Sureshkumar B, George SM, Mathew MM, Sebastian J. PowerScope a Class II corrector - a case report. Contemp Clin Dent 2016; 7(2):221-225

9. Khumanthem S, Kumar M, Ansari A, Jain A. Correction of Class II using Powerscope Appliance-a case report. Arch of Dent and Med Res 2016; 2(3):120-125

10. Hong JS, Oh KM, Kim BR, Kim YJ, Park YH. Three-dimensional analysis of pharyngeal airway volume in adults with anterior position of the mandible. Am J Orthod Dentofacial Orthop 2011; 140(4):e161-e169

11. Mahamad IK, Neela PK, Mascarenhas R, Husain A. A comparison of twin-block and Forsus (FRD) functional appliance--a cephalometric study. Int J Orthod Milwaukee 2012; 23(3):49-58

12. Heinig N, Göz G. Clinical application and effects of the Forsus spring. A study of a new Herbst hybrid. J Orofac Orthop 2001; 62(6):436-450

13. Battagel JM, Johal A, Kotecha B. A cephalometric comparison of subjects with snoring and obstructive sleep apnoea. Eur J Orthod 2000; 22(4):353-365

14. Tran KD, Nguyen CD, Weedon J, Goldstein NA. Child behavior and quality of life in pediatric obstructive sleep apnea. Arch Otolaryngol Head Neck Surg 2005; 131(1):52-57

15. Ulusoy C, Canigur Bavbek N, Tuncer BB, Tuncer C, Turkoz C, Gencturk Z. Evaluation of airway dimensions and changes in hyoid bone position following class II functional therapy with activator. Acta Odontol Scand 2014; 72(8):917-925

16. Rizk S, Kulbersh VP, Al-Qawasmi R. Changes in the oropharyngeal airway of Class II patients treated with the mandibular anterior repositioning appliance. Angle Orthod 2016; 86(6):955-961

17. Abu Allhaija ES, Al-Khateeb SN. Uvulo-glosso-pharyngeal dimensions in different anteroposterior skeletal patterns. Angle Orthod 2005; 75(6):1012-1018 